\title{
Faktor-Faktor yang Mempengaruhi Tingkat Underpricing Saham pada Perusahaan Non Keuangan yang Melakukan Initial Public Offering di Bursa Efek Indonesia Periode 2014-2018
}

\author{
Posma Sariguna Johnson Kennedy* \\ Program Studi Manajemen, Universitas Kristen Indonesia \\ Jl. Mayjen Sutoyo No.2, Cawang, Kota Jakarta Timur, Indonesia \\ posmahutasoit@gmail.com \\ Selvia Sitompul \\ Program Studi Manajemen, Universitas Kristen Indonesia \\ Jl. Mayjen Sutoyo No.2, Cawang, Kota Jakarta Timur, Indonesia \\ selviasitompul@gmail.com

\section{Suzanna Josephine Tobing} \\ Program Studi Manajemen, Universitas Kristen Indonesia \\ Jl. Mayjen Sutoyo No.2, Cawang, Kota Jakarta Timur, Indonesia \\ yosephine.tobing@uki.ac.id
}

Diterima: 09-02-2021

Disetujui: $16-06-2021$

Dipublikasi: 30-06-2021

\begin{abstract}
ABSTRAK
Fenomena underpricing terjadi di sebagian besar pasar modal dunia, termasuk Indonesia, namun dengan derajat yang berbeda-beda. Studi ini membahas analisis underpricing pada perusahaan non keuangan yang melakukan underbid saham perdana di Bursa Efek Indonesia, bertujuan membuktikan fenomena underpricing perusahaan non keuangan yang melakukan penawaran umum perdana tahun 2014-2018 dan mempelajari faktor-faktor yang mempengaruhinya. Metodologi yang digunakan dalam penelitian ini adalah metode kuantitatif dengan menggunakan regresi berganda dalam perhitungannya. Variabel yang diteliti adalah financial leverage, reputasi underwriter, dan ukuran perusahaan. Hasil pengujian membuktikan bahwa dari ketiga variabel tersebut hanya satu variabel yang tidak berpengaruh terhadap underpricing yaitu financial leverage. Variabel reputasi underwriter dan ukuran perusahaan secara parsial berpengaruh negatif terhadap underpricing, dan secara simultan ketiga variabel tersebut berpengaruh terhadap underpricing. Reputasi underwriter yang baik dan berpengalaman memberi jaminan kepada investor tentang penentuan harga terbaik saham perdana pada saat IPO (Initial Public Offering). Ukuran perusahaan menjadi pertimbangan bagi investor untuk berinvestasi dalam suatu perusahaan dengan menggunakan besaran total asetnya sebagai dasar untuk pengambilan keputusan investasi.
\end{abstract}

Kata Kunci:

Underpricing; Penawaran Umum Perdana; Financial Leverage; Reputasi Underwriter; Ukuran Perusahaan.

\begin{abstract}
The phenomenon of underpricing occurs in most of the world's capital markets, including Indonesia, but with varying degrees. This paper discusses underpricing analysis of the non-financial corporations that underbid prime shares in the Indonesia stock exchange, and aims to prove the underpricing phenomenon of non-finance companies that underpricing the Initial Public Offering by 2014-2018 while studying the factors influencing it. The methodology used to this study is quantitative method, use multiple regression in the calculations. The variable under study is financial leverage, underwriter's reputation, and company size. The results of the tests prove that of all three variables, only one variable has no effect on underpricing is financial leverage. The variable
\end{abstract}


reputation of underwriter and company size both have a partial negative effect on underpricing, and simultaneously these three variables effect on underpricing. A good and experienced underwriter reputation guarantees investors about determining the best price for the Initial Public Offering at the time of the IPO (Initial Public Offering). The size of the company is a consideration for investors to invest in a company by using the amount of its total assets as a basis for making investment decisions.

Keywords:

Underpricing; Initial Public Offering; Financial Leverage; Underwriter Reputation; Firm Size 


\section{PENDAHULUAN}

Semua perusahaan ingin melakukan perluasan dan mengembangkan usahanya, dalam melakukan pengembangan ini perusahaan memerlukan dana yang cukup besar, Perusahaan dapat memperoleh dana tersebut dari sumber dana internal ataupun eksternal. Sumber dana internal dapat diperoleh dari laba ditahan, sedangkan sumber dana eksternal dapat diperoleh dari utang bank, penerbitan saham baru, dan penerbitan surat hutang (obligasi), Salah satu altenatif eksternal yang dapat dilakukan oleh perusahaan adalah dengan cara menjual saham perusahaan kepada masyarakat atau sering disebut go public.

Perusahaan yang akan melakukan go public dapat dimulai dengan melakukan Initial Public Offerings (IPO) yang dilakukan di pasar perdana (primary market). Kemudian saham tersebut akan diperjualbelikan di pasar modal atau disebut pasar sekunder (secondary market). Harga saham pada penawaran perdana ditentukan berdasarkan kesepakatan antara perusahaan emiten dengan penjamin emisi efek (underwriter).

"Jika penentuan harga saham saat IPO secara signifikan lebih rendah dibandingkan dengan harga yang terjadi di pasar sekunder pada hari pertama maka akan terjadi underpricing" (Pahlevi, 2014). Adanya fenomena underpricing dapat dilihat pada Initial return dari hasil perbedaan harga saham ketika ditawarkan pertama kali dengan harga saham pada harga penutupan hari pertama saat diperdagangkan.

Dalam studi ini terdapat 136 perusahaan yang melakukan IPO pada periode tahun 2014 sampai dengan tahun 2018 di Bursa Efek Indonesia (BEI). Dari sekian banyak perusahaan tersebut, perusahaan non keuangan yang melakukan IPO sebanyak 119 perusahaan, yang mengalami fenomena underpricing sebanyak 107 perusahaan, yang mengalami overpricing sebanyak tujuh perusahaan, dan satu perusahaan lain yang tidak mengalami fenomena underpricing maupun overpricing seperti yang tertera pada Gambar 1.

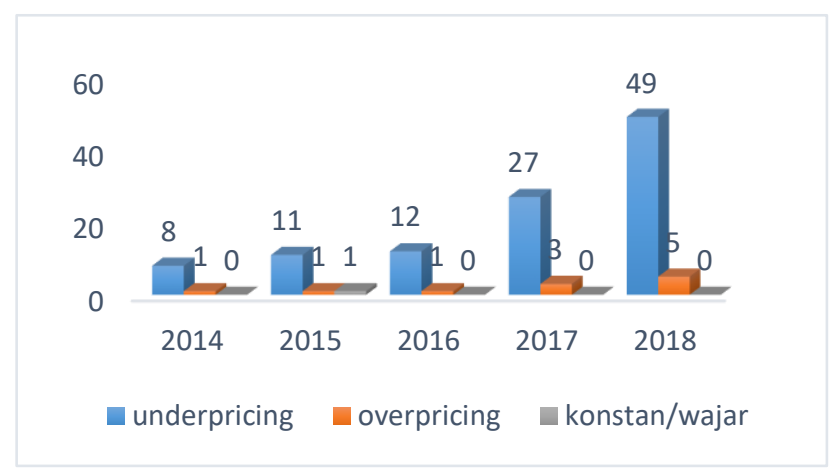

Gambar 1. Keadaan saham perusahaan yang melakukan IPO periode 2014-2018 Sumber: $w$ ww.e-bursa.com

Grafik pada Gambar 1 membuktikan bahwa perusahaan-perusahaan yang melakukan IPO lebih banyak mengalami fenomena underpricing dibandingkan dengan overpricing pada sahamnya. Adanya fenomena underpricing dapat dilihat pada Initial return dari hasil perbedaan harga saham ketika 
ditawarkan pertama kali dengan harga saham pada harga penutupan hari pertama saat diperdagangkan. Kondisi underpricing ini merugikan perusahaan yang melakukan go Public, karena dana yang diperoleh dari publik tidak maksimum. Sebaliknya jika terjadi overpricing, maka investor akan merugi, karena tidak menerima Initial return. Para pemilik perusahaan menginginkan agar meminimalisasikan situasi underpricing, karena terjadinya underpricing akan menyebabkan transfer kemakmuran dari pemilik kepada para investor (Wicaksono, 2012).

Underpricing pada penawaran umum perdana merupakan fenomena yang sering terjadi pada pasar modal diseluruh dunia. Maka perusahaan harus mengetahui faktor-faktor apa sajakah yang dapat menyebabkan fenomena underpricing ini terjadi, agar perusahaan dapat meminimalkan risiko dari fenomena underpricing tersebut. Penelitian tentang faktor-faktor underpricing pada IPO telah banyak dilakukan, namun penelitian di bidang ini masih dianggap menarik karena hasil temuannya tidak selalu konsisten.

Melihat ada banyaknya perusahaan yang mengalami fenomena underpricing dan belum adanya konsistensi hasil pada penelitian-penelitian sebelumnya, maka peneliti ingin meneliti kembali tentang faktor-faktor apa saja yang mempengaruhi underpricing. Variabel yang ditinjau dalam studi ini adalah financial leverage, reputasi underwriter, dan ukuran perusahaan.

Penawaran umum sering pula disebut go public adalah kegiatan penawaran saham atau efek yang dilakukan oleh emiten (perusahaan yang akan go public) untuk menjual saham atau efek kepada masyarakat berdasarkan tata cara yang diatur oleh Undang-Undang yang mengatur tentang pasar modal dan peraturan pelaksanaanya (Darmadji \& Fakhruddin, 2012). Underpricing merupakan salah satu fenomena yang sering ditemui ketika perusahaan akan melakukan IPO (Initial Public Offering), saham yang nantinya akan ditawarkan pada saat IPO ditentukan oleh emiten dengan underwriter. Fenomena harga rendah terjadi karena harga penawaran perdana ke publik secara rerata murah (Hartono, 2014).

Sama halnya dalam menganalisis return saham, dalam analisis underpricing juga dibutuhkan investor pemilihan investasinya (Kennedy, 2018). Pada perusahaan yang mengalami underpricing pada saat IPO dapat dipengaruhi oleh beberapa faktor, diantaranya adalah financial leverage, reputasi underwriter, dan ukuran perusahaan. Financial leverage menunjukkan proporsi penggunaan hutang untuk membiayai investasi perusahaan. Perusahaan yang tidak mempunya leverage berarti menggunakan modal sendiri 100\%" (Sartono, 2008). Semakin tinggi financial leverage yang dimiliki perusahaan maka menunjukkan risiko perusahaan yang tinggi juga, akibatnya para investor cenderung menghindari saham-saham yang memiliki nilai financial leverage (DER) yang tinggi. Dengan demikian semakin tinggi nilai DER maka semakin tinggi pula tingkat underpricing-nya. Oleh karena itu saat perusahaan yang akan melakukan IPO, perusahaan akan memperbaiki kemampuan rasio ini, karena rasio ini adalah salah satu informasi yang berguna bagi investor. Penelitian Diva (2018) mengatakan bahwa financial leverage berpengaruh signifikan terhadap underpricing. Berbanding terbalik dengan hasil penelitian Asrie (2018) bahwa financial leverage tidak memiliki pengaruh signifikan terhadap underpricing. 
Underwriter adalah penjamin emisi bagi setiap perusahaan yang akan menerbitkan sahamnya di pasar modal (Fahmi, 2013). Tugas dari pada underwriter adalah membantu menjamin perusahaan dengan porsi yang berbeda-beda. Underwriter merupakan pihak yang membuat kontrak dengan emiten untuk melakukan penawaran umum bagi kepentingan emiten dengan atau tanpa kewajiban untuk membeli sisa efek yang tidak dijual (Diva, 2018). Adanya reputasi underwriter dapat mengurangi tingkat ketidakpastian yang tidak dapat di ungkap oleh informasi yang terdapat dalam prospektus. Penelitian Rizqi \& Harto (2013) menyebutkan bahwa reputasi underwriter berpengaruh signifikan terhadap underpricing, sedangkan variabel reputasi auditor, ROE, dan leverage tidak berpengaruh signifikan terhadap underpricing. Tetapi berbanding terbalik dengan hasil penelitian Alfiah \& Lestariningsih (2017) yang mengatakan bahwa reputasi underwriter tidak berpengaruh signifikan terhadap underpricing.

Alasan pemilihan variabel reputasi underwriter adalah karena selain sebagai salah satu penentu harga saham IPO, underwriter juga merupakan motor dalam proses IPO. Underwriter yang menjadi pihak dalam menjembatani kepentingan emiten dan investor ini diduga memiliki pengaruh yang tinggi terhadap tinggi rendahnya tingkat underpricing. Emiten dapat memberikan sinyal positif kepada calon investor dengan menggunakan jasa underwriter yang berkualitas baik.

Ukuran perusahaan merupakan cerminan potensi perusahaan dalam menghasilkan arus kas dan kemampuan untuk mengakses informasi yang lebih besar. Ukuran perusahaan merupakan nilai yang menentukan besar atau kecilnya suatu perusahaan dilihat dari total asetnya yang dimilikinya. Perusahaan yang berskala besar lebih dikenal masyarakat dibandingkan dengan perusahaan kecil, ukuran perusahaan turut menentukan tingkat kepercayaan investor. Hasil penelitian Asrini (2017) mengatakan bahwa ukuran perusahaan tidak berpengaruh signifikan terhadap underpricing saham. Sedangkan hasil penelitian Wicaksono (2012) mengatakan bahwa ukuran perusahaan berpengaruh negatif terhadap underpricing.

Studi ini ingin menguji ada tidaknya pengaruh dari financial leverage, reputasi underwriter, dan ukuran perusahaan terhadap tingkat underpricing pada perusahaan yang melakukan IPO periode 2014-2018 di Bursa Efek Indonesia (BEI), dengan hipostesis sebagai berikut:

H1 : Terdapat hubungan antara tingkat underpricing dengan financial leverage.

$\mathrm{H} 2$ : Terdapat hubungan antara tingkat underpricing dengan reputasi underwriter.

H3 : Terdapat hubungan antara tingkat underpricing dengan ukuran perusahaan.

\section{METODE RISET}

Penelitian ini mengambil populasi perusahaan yang melakukan IPO di BEI tahun 2014-2018. Selama tahun 2014-2018 terdapat 136 perusahaan yang melakukan IPO di BEI, teknik pengambilan sampel dilakukan dengan purposive sampling dengan tujuan mendapatkan sampel yang respresentatif sesuai kriteria yang di tentukan. Adapun kriteria yang digunakan untuk memilih sampel adalah 
perusahaan yang melakukan IPO tahun 2014-2018, perusahaan yang tidak mengalami overpricing, dan merupakan perusahaan non keuangan. Sampel yang masuk kriteria ada 68 peruahaan.

Jenis data yang digunakan dalam penelitian ini adalah data kuantitatif yang bersifat sekunder, yaitu data yang berasal dari pihak lain yang telah dikumpulkan ataupun diolah menjadi data untuk keperluan analisis. Sumber data yang diperoleh pada penelitian ini diperoleh dari Bursa Efek Indonesia (BEI) atau Indonesia Stock Exchange (IDX), www.sahamok.com, www.e-bursa.com, dan jurnal-jurnal serta penelitian-penelitian sebelumnya.

Variabel dependen atau terikat dalam penelitian ini adalah underpricing. Underpricing dinilai dari Initial return yang merupakan pengembalian awal yang diterima oleh investor pada perusahaan non keuangan periode 2014-2018 dengan menggunakan rumus dari Yolana dan Martani (2005).

$$
\text { Underpricing }=\frac{\text { closing price }- \text { Offering Price }}{\text { Offering Price }} \times 100 \%
$$

Penelitian berfokus pada tiga varibel independen, yaitu financial leverage, reputasi underwriter, dan ukuran perusahaan. Financial leverage adalah Kemampuan perusahaan dalam membayar hutang dengan equity yang dimiliki. Rasio ini menggunakan DER yang rumusnya sebagai berikut.

$$
\text { DER }=\frac{\text { Total Hutang }}{\text { Total Ekuitas }} \times 100 \%
$$

Variabel reputasi underwriter diukur dengan kategori atau berskala non-parametrik yang dinyatakan sebagai variabel dummy dengan memberi nilai 0 dan 1 . Diukur dengan memberi nilai 1 untuk penjamin emisi yang masuk top 10 dalam 50 Most Active Stock in Trading Frequency dan nilai 0 untuk penjamin emisi yang tidak masuk to 10 (Ghozali, 2005).

Ukuran perusahaan yang digunakan dalam penelitian ini adalah total asset perusahaan untuk tahun terakhir sebelum go public. (Yolana dan Martani, 2005). Pada penelitian ini penulis menggunakan analisis regresi linear berganda (Multiple Linear Regression Analysis), dengan bantuan SPSS 22. Peneliti melakukan uji asumsi klasik terlebih dahulu sebelum melakukan pengujian hipotesis.

Metode analisis regresi linear berganda digunakan untuk meramalkan suatu variabel dependen $\mathrm{Y}$ berdasarkan dua atau lebih variabel independen $(\mathrm{X} 1, \mathrm{X} 2, \mathrm{X} 3)$ dalam suatu persamaan linear. Berikut model regresi berganda:

$$
Y=\alpha+\beta_{1 X 1}+\beta_{2} x_{2}+\beta_{3} x_{3}+\varepsilon_{j}
$$

Dimana:

$\mathrm{Y}=$ variabel terikat

$\alpha=$ konstanta

$\mathrm{x}_{1}=$ financial leverage

$\mathrm{x}_{2}=$ reputasi underwriter

$\mathrm{x}_{3}=$ ukuran perusahan $\beta_{1}=$ koefisiensi regresi financial leverage

$\beta_{2}=$ koefisiensi regresi reputasi underwriter

$\beta_{3}=$ koefisiensi regresi ukuran perusahaan;

$\varepsilon=$ standart error 
Kannedy, P.S.J., Sitompul, S. \& Tobing, J. (2021). Faktor-Faktor yang Mempengaruhi Tingkat ....

\section{HASIL PENELITIAN DAN PEMBAHASAN}

\section{Analisis Statistik Deskriptif}

Nilai underpricing yang diukur dengan cara perhitungan harga saham saat penutupan pasar primer (closing price) di kurang dengan harga saham saat IPO dibagi dengan harga saham saat IPO. Diperoleh data underpricing pada 68 perusahaan sebagai berikut:

Tabel 1. Data Nilai Underpricing

\begin{tabular}{|c|c|c|}
\hline No & Nama Perusahaan & Under-Pricing \\
\hline 1 & Link Net Tbk & 0.500 \\
\hline 2 & Chitose Internasional Tbk & 0.100 \\
\hline 3 & Sitara Propertindo Tbk & 0.698 \\
\hline 4 & Soechi Lines Tbk & 0.127 \\
\hline 5 & Impack Pratama Industri Tbk & 0.500 \\
\hline 6 & Mitra Energi Persada Tbk & 0.493 \\
\hline 7 & Mega Manunggal Property Tbk & 0.495 \\
\hline 8 & Binakarya Jaya Abadi Tbk & 0.500 \\
\hline 9 & Mitra Komunikasi NTbk & 0.700 \\
\hline 10 & Kino Indonesia Tbk & 0.013 \\
\hline 11 & Mahaka Radio Integra Tbk & 0.026 \\
\hline 12 & Cikarang Listrindo Tbk & 0.026 \\
\hline 13 & Sillo Maritime Perdana Tbk & 0.700 \\
\hline 14 & Graha Andrasentra P Tbk & 0.235 \\
\hline 15 & Waskita Beton Precast Tbk & 0.102 \\
\hline 16 & Paramita Bangun Sarana Tbk & 0.050 \\
\hline 17 & Prodia Widyahusada Tbk & 0.015 \\
\hline 18 & Bintang Oto Global Tbk & 0.699 \\
\hline 19 & Sanurhasta Mitra Tbk & 0.695 \\
\hline 20 & Sariguna Primatirta Tbk & 0.695 \\
\hline 21 & Cahayasakti Investindo S Tbk & 0.500 \\
\hline 22 & Pelayaran Tamarin S Tbk & 0.700 \\
\hline 23 & Terregra Asia Energy Tbk & 0.700 \\
\hline 24 & Alfa Energi Investama Tbk & 0.500 \\
\hline 25 & Totalindo Eka Persada Tbk & 0.490 \\
\hline 26 & Kirana Megatara Tbk & 0.495 \\
\hline 27 & Armidian Karyatama Tbk & 0.500 \\
\hline 28 & Integra Indocabinet Tbk & 0.076 \\
\hline 29 & Hartadinata Abadi Tbk & 0.106 \\
\hline 30 & Buyung Poetra Sembada & 0.103 \\
\hline 31 & Marga Abhinaya Abadi Tbk & 0.696 \\
\hline 32 & Mark Dynamics Indonesia Tbk & 0.496 \\
\hline 33 & Ayana Land International Tbk. & 0.699 \\
\hline 34 & Trisula Textile Industries Tbk & 0.193 \\
\hline 35 & Kapuas Prima Coal Tbk & 0.700 \\
\hline 36 & M Cash Integrasi Tbk & 0.494 \\
\hline 37 & Wijaya Karya Bangunan GTbk & 0.020 \\
\hline 38 & Pelita Samudera Shipping Tbk & 0.111 \\
\hline 39 & Campina Ice Cream I Tbk & 0.496 \\
\hline 40 & Jasa Armada Indonesia Tbk & 0.057 \\
\hline 41 & LCK Global Kedaton Tbk & 0.500 \\
\hline 42 & Jaya Trishindo Tbk & 0.700 \\
\hline 43 & Sky Energy Indonesia Tbk & 0.500 \\
\hline 44 & Indah Prakasa Sentosa Tbk & 0.500 \\
\hline 45 & Tridomain Performance M Tbk & 0.500 \\
\hline 46 & Gihon Telekomunikasi I Tbk & 0.500 \\
\hline 47 & Surya Pertiwi Tbk & 0.025 \\
\hline 48 & Royal Prima Tbk & 0.500 \\
\hline 49 & Sarimelati Kencana Tbk & 0.004 \\
\hline 50 & Guna Timur Raya Tbk & 0.495 \\
\hline
\end{tabular}




\begin{tabular}{clc}
\hline No & \multicolumn{1}{c}{ Nama Perusahaan } & Under-Pricing \\
\hline 51 & Sriwahana Adityakarta Tbk & 0.700 \\
52 & Trimuda Nuansa Citra Tbk & 0.693 \\
53 & Batavia Prosperindo Trans Tbk & 0.700 \\
54 & Mahkota Group Tbk & 0.502 \\
55 & NFC Indonesia Tbk & 0.497 \\
56 & Sinergi Megah Internusa Tbk & 0.693 \\
57 & Andira Agro Tbk & 0.700 \\
58 & Trimitra Propertindo Tbk & 0.500 \\
59 & Arkadia Digital Media Tbk & 0.700 \\
60 & Pratama Abadi Nusa I Tbk & 0.694 \\
61 & Natura City Developments Tbk & 0.700 \\
62 & Cottonindo Ariesta Tbk & 0.690 \\
63 & Garudafood Putra Putri J Tbk & 0.498 \\
64 & Yelooo Integra Datanet Tbk & 0.489 \\
65 & Shield On Service Tbk & 0.500 \\
66 & Satria Mega Kencana Tbk & 0.696 \\
67 & Urban Jakarta Propertindo Tbk & 0.500 \\
68 & Mega Perintis Tbk & 0.496 \\
\hline \multicolumn{2}{c}{ Sumber : diolah oleh penulis }
\end{tabular}

Analisis statistik deskriptif dari data yang diambil untuk penelitian ini adalah 68 perusahaan dengan periode tahun 2014-2018.

Tabel 2. Statistic Deskriptif

\begin{tabular}{lrrrrr}
\hline & $\mathrm{N}$ & \multicolumn{1}{c}{ Mini-mum } & Maxi-mum & \multicolumn{1}{c}{ Mean } & Std. Deviasi \\
\hline Financial Leverage & 68 & .030 & 3.600 & 1.369 & .9928 \\
Reputasi Underwritter & 68 & 0 & 1 & .44 & .500 \\
Ukuran Perusahaan & 68 & 21.53 & 29.85 & 26.10 & 1.8972 \\
Tingkat Underpricing & 68 & .004 & .700 & .4510 & .2439 \\
Valid N (listwise) & 68 & & &
\end{tabular}

Tabel diatas terlihat bahwa variabel dependen yaitu underpricing memiliki nilai minimum 0,004, nilai maksimum 0,700 dan nilai rata-rata sebesar 0,45107 dengan standar deviasi sebesar 0,243901, financial leverage memiliki nilai minimum 0,003 dan nilai maksimum 3,600, dengan nilai rata-rata sebesar 1,36971 dan standar deviasi 0,992854. Variabel reputasi underwriter menggunakan variabel dummy 1 untuk underwriter yang memiliki reputasi baik dan 0 untuk underwriter yang memiliki reputasi kurang baik, mempunyai nilai rata-rata sebesar 0.44 dengan standar deviasi. 0.500.

\section{Uji Asumsi Klasik}

Dalam penelitian ini, penulis menggunakan metode regresi berganda. Uji asumsi klasik adalah persyaratan statistik yang harus dipenuhi.

\section{Uji Normalitas}

Deteksi terhadap univariate outlier dapat dilakukan dengan menentukan nilai batas yang akan dikategorikan sebagai data outlier yaitu dengan cara mengkonversi nilai data kedalam skor standardized atau yang biasa disebut $Z$-score, yang nilai means (rata-rata) sama dengan nol dan standar deviasi sama dengan satu. Dalam hal ini dilakukan penghapusan 39 sampel yang nilainya jauh dari nilai sampel lain 
untuk membuat data normal. Jumlah sampel yang digunakan dalam penelitian ini adalah sebanyak 68 perusahaan.

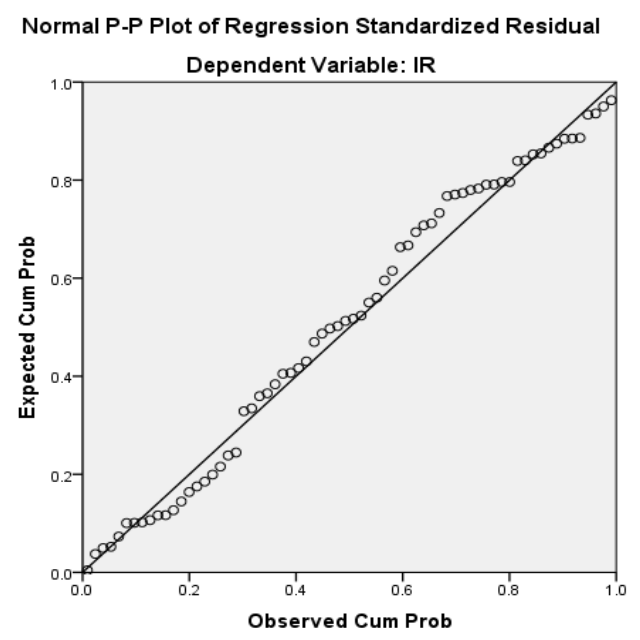

Gambar 2. Hasil Uji Normalitas Setelah Outlier Sumber : data diolah penulis, spss 22

Dari gambar grafik normalitas di atas, menunjukkan bahwa titik-titiknya mengikuti garis diagonal. Dengan demikian grafik ini menunjukkan bahwa data terdistribusi normal. Metode lain yang dapat digunakan dalam pengujian normalitas adalah dengan menggunakan Uji Kolmogrov Smirnov dengan menguji nilai residualnya.

Tabel 3. Uji Normalitas Setelah Outlier One-Sample Kolmogorov-Smirnov Test

\begin{tabular}{llc}
\hline & & One-Sample Kolmogorov-Smirnov Test \\
\hline $\mathrm{N}$ & & Unstandardized Residual \\
Normal & Mean & 68 \\
Parameters ${ }^{\mathrm{a} b}$ & Std. Deviation & .0000000 \\
Most Extreme & Absolute & .20303119 \\
Differences & Positive & .096 \\
& Negative & .056 \\
Test Statistic & & -.096 \\
Asymp. Sig. (2-tailed) & .096 \\
\multicolumn{2}{c}{ Sumber : data diolah penulis, spss 22}
\end{tabular}

Berdasarkan tabel diatas terlihat bahwa data untuk variabel dependen dan variabel independen berdistribusi normal, terlihat dari keterangan di atas bahwa tabel dan nilai signifikansi sebesar 0,196 > 0,05. Disimpulkan data berdistribusi normal.

\section{Uji Multikolinearitas}

Tabel 4. Hasil Uji Multikolinearitas

\begin{tabular}{llcc}
\hline \multicolumn{1}{c}{ Model } & \multicolumn{2}{c}{ Collinearity Statistics } \\
& Tolerance & VIF \\
\hline 1 (Constant) & & \\
LEVERAGE & .743 & 1.347 \\
UNDERWRITER & .936 & 1.068 \\
UKURAN & .705 & 1.419 \\
\hline \multicolumn{2}{c}{ Sumber : data diolah penulis, spss 22}
\end{tabular}


Dari Tabel diatas dapat dilihat bahwa nilai tolerance semua variabel independen $>0,10$ dan begitu juga nilai VIF $<10$. Sehingga dalam penelitian ini tidak terjadi multikolinearitas dalam model regresinya.

\section{Uji Heterokedastisitas}

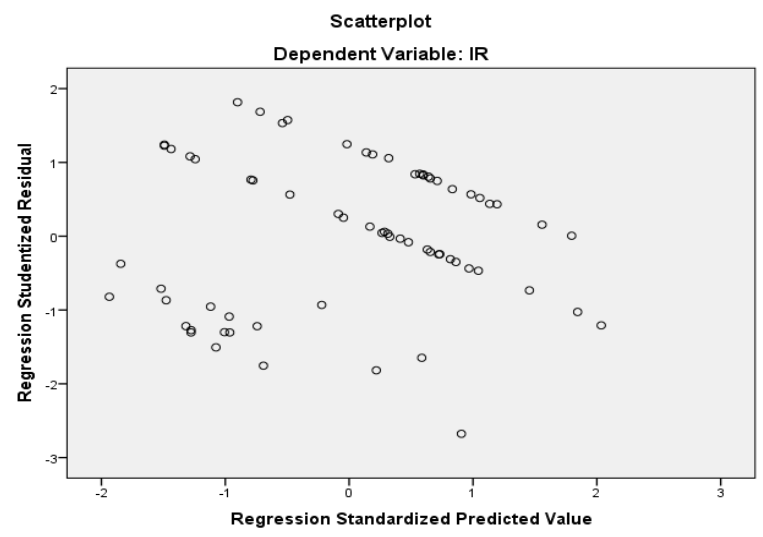

Gambar 3. Hasil Uji Heterokedastisitas

Sumber : data diolah penulis, spss 22

Grafik scatterplot pada gambar diatas menunjukkan bahwa tampak titik-titik tidak membentuk pola tertentu. Maka dapat dikatakan bahwa regresi tidak mengandung adanya heterokedastisitas.

\section{Uji Autokorelasi}

Berdasarkan perhitungan diperoleh nilai Durbin Watson sebesar 1,806. Sedangkan dalam gambar posisi angka Durbin Watson untuk $\mathrm{k}=4$ dan $\mathrm{N}=68$ diperoleh hasil $d l$ (batas luar) $=1.4853$ dan $d u$ (batas dalam) $=1.7335 ; 4-d u=2.2665$ dan $4-d l=2.5147$, maka dari perhitungan disimpulkan bahwa Durbin Watson Test sebesar 1.806 terletak pada daerah tidak ada autokorelasi. Model regresi yang baik adalah regresi yang bebas dari autokorelasi.

Tabel 5. Hasil Uji Autokorelasi Model Summary

\begin{tabular}{cccccc}
\hline Model & $\mathrm{R}$ & R Square & Adjusted R Square & Std. Error & Durbin-Watson \\
\hline 1 & $.554^{\mathrm{a}}$ & .307 & .275 & .207735 & 1.806 \\
\hline
\end{tabular}

a. Predictors: (Constant), UKURAN, UNDERWRITER, LEVERAGE

b. Dependent Variable: IR

Sumber : data diolah penulis, spss 22

\section{Regresi Berganda}

Tabel 6. Hasil Regresi Berganda

\begin{tabular}{lccc}
\hline \multirow{2}{*}{ Model } & \multicolumn{2}{c}{ Unstandardized Coefficients } & Standardized Coefficients \\
\cline { 2 - 4 } & $\mathrm{B}$ & Std. Error & Beta \\
\hline 1 (Constant) & 1.690 & .393 & .080 \\
LEVERAGE & .020 & .030 & -.380 \\
UNDERWRITER & -.185 & .052 & -.353 \\
UKURAN & -.045 & .016 &
\end{tabular}

Pada di atas dapat dijelaskan bahwa persamaan regresi berganda adalah:

$Y=1,690+0,020 \times 1-0,185 \times 2-0,045 \times 3$ 
Kannedy, P.S.J., Sitompul, S. \& Tobing, J. (2021). Faktor-Faktor yang Mempengaruhi Tingkat ....

Hasil tersebut menunjukkan bahwa financial leverage memiliki arah koefisien positif, sedangkan reputasi underwriter dan ukuran perusahaan memiliki arah negatif.

\section{Uji Hipotesis}

Uji t

Tabel 7. Hasil Uji t

\begin{tabular}{lccccc}
\hline \multirow{2}{*}{ Model } & \multicolumn{2}{c}{ Unstandardized Coefficients } & Standardized Coefficients & \multirow{2}{*}{ Sig. } \\
\cline { 2 - 4 } & $\mathrm{B}$ & Std. Error & Beta & & \\
\hline 1 (Constant) & 1.690 & .393 & & & \\
LEVERAGE & .020 & .030 & .080 & .662 & .510 \\
UNDERWRITER & -.185 & .052 & -.380 & -3.531 & .001 \\
UKURAN & -.045 & .016 & -.353 & -2.848 & .006 \\
\hline \multicolumn{7}{l}{ Sumber $:$ data diolah oleh penulis, spss 22} & &
\end{tabular}

Pengaruh tiap variabel independen terhadap variabel dependen dapat dijelaskan berikut ini:

1. Variabel financial leverage menunjukkan nilai positif dengan $t$-hitung sebesar 0,662 lebih kecil dari $t$-tabel 1,69389 dan signifikansi sebesar 0,510 lebih besar dari 0,05. Hal ini berarti hipotesis (H1) yang menyatakan bahwa financial leverage berhubungan dan signifikan terhadap peristiwa underpricing ditolak.

2. Variabel reputasi underwriter menunjukkan nilai negatif dari $t$-hitung sebesar 3.531 lebih besar dari $t$-tabel 1,69389 dan tingkat signifikansi sebesar 0,001 lebih kecil dari 0,05. Hal ini berarti hipotesis (H2) tidak ditolak yang menyatakan bahwa reputasi underwriter berpengaruh dan signifikan terhadap peristiwa underpricing dengan arah negatif

3. Variabel ukuran perusahaan menunjukkan nilai negatif dengan $t$-hitung sebesar 2,848 lebih besar dari $t$-tabel 1,69389, dan tingkat signifikansi sebesar 0,006 lebih kecil dari 0,05. Hal ini berarti hipotesis (H3) tidak ditolak yang menyatakan bahwa ukuran perusahaan berpengaruh dan signifikan terhadap peristiwa underpricing dengan arah negatif.

Uji F

Tabel 8. Uji F statistik

\begin{tabular}{lccccc}
\hline \multicolumn{1}{c}{ Model } & Sum of $S q$. & $d f$ & Mean Square & $F$ & Sig. \\
\hline 1 Regression & 1.224 & 3 & .408 & 9.453 & $.000^{\mathrm{b}}$ \\
Residual & 2.762 & 64 & .043 & & \\
Total & 3.986 & 67 & & & \\
\hline
\end{tabular}

Sumber : data diolah penulis, spss 22

Dari perhitungan dan output spss, diperoleh hasil bahwa nilai uji F-hitung sebesar 9.453 lebih besar dari Ftabel sebesar 2,51 dan tingkat signifikansi 0,000 lebih kecil dari 0,05. Artinya secara simultan bersama-sama variabel independen mempengaruhi peristiwa underpricing.

\section{Koefisien Determinasi}

Dari perhitungan dan output spss, menunjukkan koefisien determinasi ( $R$ square) mempunyai nilai sebesar 0,275. Hal ini berarti variabel independen (financial leverage, reputasi underwriter, dan ukuran perusahaan) mempengaruhi underpricing sebesar 27,5\%, sedangkan 72,5\% dipengaruhi oleh faktor-faktor lain diluar model ini. 
Tabel 9. Koefisien Determinasi

\begin{tabular}{cccc}
\hline Model & R & R Square & Adjusted R Square \\
\hline 1 & $.554^{\mathrm{a}}$ & .307 & .275 \\
\hline \multicolumn{4}{c}{ Sumber $:$ data diolah penulis, spss 22}
\end{tabular}

\section{Pembahasan}

Perusahaan yang ingin melakukan IPO, disarankan agar memperhatikan siapa yang menjadi underwriter untuk perusahaan. Reputasi underwriter yang baik dapat mengurangi tingkat underpricing saham karena dapat memprediksi harga dimasa yang akan datang dengan baik. Perusahaan dapat menggunakan underwriter yang masuk dalam top 10 penjamin emisi terbaik yang setiap tahunnya di publikasikan oleh Bloomberg.com.

Perusahaan juga harus memperhatikan ukuran perusahaan, karena investor lebih tertarik dengan perusahaan yang memiliki ukuran besar. Dalam penelitian ini digambarkan melalui nilai total aset perusahaan. Nilai yang lebih besar mempunyai kepastian yang lebih besar daripada perusahaan kecil, sehingga akan mengurangi tingkat ketidakpastian mengenai prospek perusahaan ke depan. Untuk itu diharapkan perusahaan dapat meningkatkan kemampuan perusahaan dalam beroperasional dan mengembangkan usahanya.

Bagi investor yang berminat untuk membeli saham melalui pasar modal, hasil penelitian ini bisa menjadi referensi dalam melakukan pembelian. Para investor harus melihat profil perusahaan dan juga profil underwriter yang digunakan, karena underwriter yang memiliki reputasi tingi justru tingkat underpricing semakin rendah. Memang investor akan kurang mendapat keuntungan yang maksimal jika berinvestasi pada perusahaan yang menggunakan underwriter dengan reputasi tinggi. Para investor terlebih dahulu melihat laporan keuangan yang diterbitkan oleh perusahaan, agar dapat dengan mudah memilih perusahaan yang akan diinvestasikan

\section{KESIMPULAN DAN SARAN}

Berdasarkan hasil analisis data dan pembahasan yang sudah diuraikan, dapat ditarik beberapa kesimpulan. Variabel financial leverage tidak memiliki pengaruh terhadap fenomena underpricing saham pada perusahaan yang melakukan IPO pada tahun 2014-2018 di Bursa Efek Indonesia. Hal ini dikarenakan financial leverage lebih mencerminkan risiko perusahaan. Investor cenderung menghindari saham-saham yang memiliki risiko tinggi.

Secara parsial variabel reputasi underwriter dan ukuran perusahaan berpengaruh negatif signifikan terhadap fenomena underpricing saham pada perusahaan yang melakukan IPO pada tahun 2014-2018 di Bursa Efek Indonesia. Reputasi underwriter yang baik dan pengalaman yang dimilikinya akan menjadi jaminan kepada investor tentang penentuan harga terbaik saham perdana pada saat IPO. Ukuran perusahaan menjadi pertimbangan bagi investor untuk berinvestasi dalam suatu perusahaan. Para investor menggunakan besaran perusahaan yang diukur dengan total asset sebagai dasar untuk pengambilan keputusan investasi. 
Kannedy, P.S.J., Sitompul, S. \& Tobing, J. (2021). Faktor-Faktor yang Mempengaruhi Tingkat ....

Secara simultan ketiga variabel financial leverage, reputasi underwriter, dan ukuran perusahaan bersama-sama berpengaruh signifikan terhadap fenomena underpricing saham pada perusahaan yang melakukan IPO. Dengan demikian perusahaan yang ingin melakukan IPO, disarankan agar memperhatikan siapa yang menjadi underwriter untuk perusahaan. Reputasi underwriter yang baik dapat mengurangi tingkat underpricing saham karena dapat memprediksi harga dimasa yang akan datang dengan baik. Perusahaan juga harus memperhatikan ukuran perusahaan, karena investor lebih tertarik dengan perusahaan yang memiliki ukuran besar.

Dalam peneliti selanjutnya diharapkan dapat menambah dan menggunakan variabel lain yang dimungkinkan mempengaruhi tingkat underpricing saham, serta memperbesar jumlah observasi dan memperpanjang jumlah tahun yang dijadikan sampel penelian. 


\section{DAFTAR PUSTAKA}

Alfiah, W. N. dan M. Lestariningsih. (2017). Pengaruh DPS, EPS, NPM, ROA terhadap Harga Saham. Jurnal Ilmu dan Riset Manajemen. 6 (9).

Asrie, Shinta Puspita. (2018). Faktor-faktor yang memperngaruhi tingkat underpricing pada perusahaan yang melakukan Initial Public Offering di Bursa Efek Indonesia, Jurnal Universitas Islam Indonesia, Yogyakarta.

Asrini. (2017). Model underpricing pada penawaran umum perdana (IPO) pada perusahaan Go Public, Jurnal STIE Muhammadiyah, Jambi.

Bloomberg. https://www.bloomberg.com/asia

Darmadji, Tjiptono, dan Fakhruddin. (2012). Pasar Modal Di Indonesia. Edisi. Ketiga. Jakarta: Salemba Empat.

Diva, Riyanti Arintia, (2018). Analisis faktor-faktor yang mempengaruhi underpricing saham pada saat Initial Public Offering (IPO) di Bursa Efek Indonesia tahun 2010-2015, Jurnal Universitas Lampung, Lampung.

Fahmi, Irham. (2013). Analisis Laporan Keuangan, Alfabeta, Bandung.

Fakhruddin, Hendy M. (2008). Istilah Pasar Modal A-Z. Jakarta: Gramedia.

Ghozali, Imam. (2009). Aplikasi Analisis Multivariate dengan Program SPSS. Semarang: UNDIP.

Hartono, Jogiyanto. (2014). Metode Penelitian Bisnis, Edisi Keenam. Yogyakarta: Universitas Gadjah Mada, Yogyakarta.

Indonesia Stock Exchange(IDX). https://www.idx.co.id/en-us/

Pahlevi, Reza Widhar. (2014). Analisis Faktor-Faktor Yang Mempengaruhi Underpricing Saham Pada Penawaran Saham Perdana Di Bursa Efek Indonesia, Jurnal Universitas Islam Indonesia.

P.S.J. Kennedy, R. Hayrani. (2018). Pengaruh Faktor-Faktor Ekonomi Makro: Inflasi, Kurs, Harga Minyak,dan Harga Bahan Bangunan terhadap Harga Saham Perusahaan Properti di BEI, Jurnal Mitra Manajemen (JMM Online), Vol 2, No.1, 2018, 1-12.

Risqi, Indita Azisia dan Harto, Puji. (2013). Analisis Faktor-Faktor yang Mempengaruhi Underpricing 
Kannedy, P.S.J., Sitompul, S. \& Tobing, J. (2021). Faktor-Faktor yang Mempengaruhi Tingkat ....

Ketika Initial Public Offering (IPO) di Bursa Efek Indonesia, Journal Of Accounting, Vol. 2. No. 3. Hal. 1-7.

Sartono, Agus. (2008). Manajemen Keuangan Teori dan Aplikasi. Edisi Empat. Yogyakarta: BPFE

Wicaksono, Nur Azizi. (2012). Analisis Pengaruh Variabel Keuangan dan Non Keuangan Terhadap Fenomena Underpricing Saham Perdana Saat Initial Public Offering, Skripsi Universitas Indonesia.

Yolana, C., \& Martani, D. (2005). Variabel - Variabel yang Mempengaruhi Fenomena Underpricing Pada Penawaran Saham Perdana DI BEJ Tahun 1994-2001. SNA VIII September 2005, Solo, 538-553.

www.sahamok.com,

www.e-bursa.com. 